\title{
Utilizarea ibuprofenului în febră, durere şi inflamație la copii
}

\author{
Simona Negreş \\ Disciplina de Farmacologie şi Farmacie clinică, Facultatea de Farmacie, Universitatea de \\ Medicină şi Farmacie „Carol Davila“, Bucureşti, România
}

\begin{abstract}
REZUMAT
Ibuprofenul este un antiinflamator nesteroidian (AINS) din clasa derivaţilor de acid propionic, utilizat astăzi pe scară largă atât la adulţi, cât şi la copii, pentru tratamentul durerii, febrei şi inflamaţiei de diverse etiologii. Studii clinice randomizate, controlate activ sau cu placebo, susţin eficacitatea ibuprofenului, administrat ca monoterapie sau în asocieri, în doză unică sau doze repetate, în aceste stări patologice. Datele de siguranţă publicate în literatură arată faptul că ibuprofenul este unul dintre cele mai utilizate AINS - pe de o parte datorită eficacităţii, iar pe de altă parte datorită profilului redus de reacţii adverse.
\end{abstract}

Cuvinte cheie: ibuprofen, durere, inflamaţie, febră, copii, paracetamol, otalgie, dureri în gât

\section{INTRODUCERE}

Ibuprofenul este cel mai utilizat medicament din clasa antiinflamatoarelor nesteroidiene pentru tratamentul inflamaţiei, febrei şi al durerii uşoare sau moderate, având un profil de siguranţă crescut. Mecanismul principal prin care reduce febra, inflamaţia şi durererea la copii constă în scăderea sintezei de prostaglandine proinflamatoare la nivel central şi periferic.

\section{Eficacitatea ibuprofenului ca analgezic şi antipiretic la copii}

Eficacitatea ibuprofenului a fost evaluată comparativ cu alte medicamente antipiretice: paracetamol, noraminofenazonă, ketoprofen, la copii febrili (cu febră cauzată de infecţii virale sau bacteriene). În aceste studii, pacienţii pediatrici au primit o scală largă de doze de ibuprofen: 4-5-10-15 mg/kg corp/doză, în funcţie de vârsta acestora. Rezultatele studiilor clinice au arătat că ibuprofenul este eficient în reducerea febrei, durerii şi inflamaţiei, cu un debut mai rapid al efectului şi cu menţinerea acestuia timp de 6 ore. Alte studii au evaluat regimuri de tratament prin alternarea administrării de ibuprofen şi paracetamol comparativ cu monoterapia.
Rezultatele acestora sunt controversate, unele susţinând o eficacitate superioară pentru terapia alternantă, iar altele infirmând acest lucru. Alte studii efectuate la copii au subliniat reducerea incidenţei reacţiilor adverse date de vaccinare prin administrarea profilactică a ibuprofenului $(12,20)$ în doze de $10-15 \mathrm{mg} / \mathrm{kg} /$ doză. În tabelul 1 sunt redate câteva dintre studiile comparative de de eficacitate, mai recente, ale ibuprofenului la copii.

Cea mai recentă citare din literatură este o metaanaliză publicată de Poddighe et al. (2018) (28) în Pediatric Emergency, care are un titlu sugestiv: „Ibuprofenul în controlul durerii la copii - nouă valoare pentru o moleculă veche“. Autorii şi-au propus să discute dovezile actuale, publicate în bazele de date PubMed şi Medline în perioada 1985-2017, privind utilizarea ibuprofenului în condiţii clinice specific diferite şi să realizeze o comparaţie cu paracetamolul şi/sau codeina conform studiilor disponibile. S-au avut în vedere următoarele indicaţii pediatrice: dureri de gât, dureri de urechi, dureri dentare, dureri de cap, dureri musculo-scheletice posttraumatice şi dureri postoperatorii.

Pentru durerea de gât au fost selectate două studii dublu-orb randomizate placebo-controlate (SDORC) $(3,32)$, care au comparat eficacitatea ibu- 
TABELUL 1. Studii clinice de eficacitate ale ibuprofenului pentru tratarea durerii, febrei şi inflamației la copii

\begin{tabular}{|c|c|c|}
\hline Referința & Obiectivul studiului & Concluzii \\
\hline $\begin{array}{l}\text { Perrot şi colab., } \\
2004 \text { (26) }\end{array}$ & $\begin{array}{l}\text { Inves åạ e a@ităţii şi siguranţei } \\
\text { ibuprofenului la copii (186) febrili compara } \\
\text { cu paracetamolul }\end{array}$ & 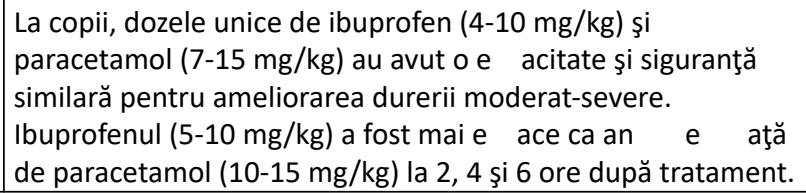 \\
\hline $\begin{array}{l}\text { Goldman şi colab., } \\
2004 \text { (9) }\end{array}$ & 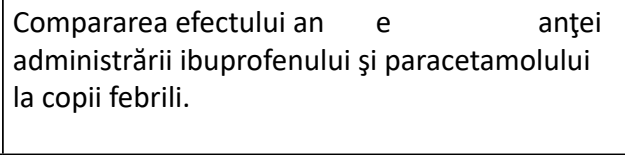 & $\begin{array}{l}\text { Au fost analizate publicaţii din bazele de date MEDLINE (1966- } \\
\text { 2003) şi EMBASE (1988-2003). Ibuprofenul a fos a } \\
\text { mai e t decât paracetamolul în reducerea febrei după o } \\
\text { singură doză, cu menţinerea efectului } 6 \text { ore pos atęment. }\end{array}$ \\
\hline $\begin{array}{l}\text { Hay şi colab., } 2009 \\
\text { (11) }\end{array}$ & $\begin{array}{l}\text { Compararea e a®tăţii an e ? } \\
\text { paracetamolului }(15 \mathrm{mg} / \mathrm{kg} ; 4 \text { doze } / 24 \text { ore) şi } \\
\text { ibuprofenului }(10 \mathrm{mg} / \mathrm{kg} ; 3 \text { doze } / 24 \text { ore) la copii } \\
\text { febrili }\left(\geq 37,8^{\circ} \mathrm{C} ;<40^{\circ} \mathrm{C}\right) .\end{array}$ & \begin{tabular}{|lr} 
Ibuprofenul a fost mai e & t şi mai rapid în reducerea febrei \\
la copii, compara & acetamolul.
\end{tabular} \\
\hline $\begin{array}{l}\text { Paul şi colab., } 2010 \\
(25)\end{array}$ & $\begin{array}{l}\text { Studiu compara a@itate pentru } \\
\text { evaluarea efectului an e ? opii } \\
\text { cu } 3 \text { regimuri de tratament: ibuprofen } \\
\text { în monoterapie, ibuprofen combinat cu } \\
\text { paracetamol, ibuprofen urmat de paracetamol } \\
\text { (perioada de observare } 6 \text { ore). }\end{array}$ & $\begin{array}{l}\text { E ađitatea a fost mai mare în caz ării şchemelor de } \\
\text { tratament cu asocieri între ibuprofen şi paracetamol. }\end{array}$ \\
\hline $\begin{array}{l}\text { Sarell şi colab., } \\
2006(30)\end{array}$ & $\begin{array}{l}\text { Compararea e aबtăţii an e ? azu@ } \\
\text { administrării ibuprofenului ( } 5 \mathrm{mg} / \mathrm{kg} \text { la } 8 \text { ore) } \\
\text { şi paracetamolului ( } 12,5 \mathrm{mg} / \mathrm{kg} \text { la } 6 \text { ore) ca } \\
\text { monoterapie sau ca terapie alternantă (ambele } \\
\text { medicamente) la copii cu vârsta cuprinsă între } \\
\text { 6-36 luni. }\end{array}$ & $\begin{array}{l}\text { Tratamentul alternant cu paracetamol } 12,5 \mathrm{mg} / \mathrm{kg} \text { şi ibuprofen } \\
5 \mathrm{mg} / \mathrm{kg} \text { administrate la } 4 \text { ore } \mathrm{s} \text {-a dovedit mai e t în } \\
\text { reducerea febrei compara }\end{array}$ \\
\hline $\begin{array}{l}\text { Magni şi colab., } \\
2011 \text { (18) }\end{array}$ & $\begin{array}{l}\text { Compararea e a®tăţii şi siguranţei } \\
\text { ibuprofenului şi noraminofenazonei la copii (80) } \\
\text { febrili cu vârsta cuprinsă între } 6 \text { luni-8 ani. }\end{array}$ & $\begin{array}{l}\text { O doză unică de ibuprofen a avut o e ađitate an e 菑回 } \\
\text { superioară noraminofenazonei. }\end{array}$ \\
\hline $\begin{array}{l}\text { Wong şi colab. } \\
2014(36)\end{array}$ & $\begin{array}{l}\text { Compararea e a®tăţii monoterapiei cu } \\
\text { ibuprofen sau paracetamol cu un regim în } \\
\text { care cele două medicamente se administrează } \\
\text { alterna . . . }\end{array}$ & $\begin{array}{l}\text { Ibuprofenul şi paracetamolul administrate ca monoterapie } \\
\text { au redus la fel de e t febra compara } \\
\text { administrare alterna ă[? }\end{array}$ \\
\hline
\end{tabular}

profenului cu placebo şi paracetamol şi care au concluzionat că ambele medicamente au fost la fel de eficace. Concluzii similare au reieşit dintr-o meta-analiză mai recentă (27) asupra siguranţei şi eficacităţii ibuprofenului şi paracetamolului atât la copii, cât şi la adulţi.

Ambele medicamente sunt recomandate în câteva ghiduri pentru acest tip de durere fără a se decide încă o abordare unitară sub forma terapiei combinate. În cazuri selectate, cu componentă exudativă majoră şi/sau adenopatie locală, inclusiv în faringita cu streptococ din grupul A, ibuprofenul este preferat datorită proprietăţilor sale antiinflamatorii (5).

Pentru otalgie s-a luat în considerare studiul publicat de Bertin şi colab. (1991) (3), care a inclus 219 copii (cu vârsta cuprinsă între 1 şi 6 ani) cu otită medie, trataţi cu ibuprofen timp de 48 de ore. Eficacitatea celor două substanţe active a fost comparabilă.

O evaluare sistematică a literaturii recente (33) privind eficacitatea paracetamolului şi antiinflamatoarelor nesteroidiene, inclusiv ibuprofenul, în tratamentul otitei medii a concluzionat echivalenţa terapeutică a ambelor medicamente la 24 şi 48 ore, fără diferenţe în ceea ce priveşte profilul de reacţii adverse. Mai mult decât atât, nu s-a documentat superioritatea combinaţiei ibuprofen-paracetamol faţă de monoterapie.

Pentru durerea dentară (dată de carii sau după proceduri stomatologice), ibuprofenul s-a dovedit a fi mai eficient faţă de paracetamol (1). De subliniat este un studiu pediatric efectuat pe copii cu vârsta cuprinsă între 5 şi 12 ani, cu dureri dentare, în care ibuprofenul a controlat durerea la fel de eficient ca şi asocierea paracetamol-codeină (23). Un alt studiu pediatric, efectuat la copii cu vârsta cuprinsă între 12 şi 16 ani supuşi unor proceduri stomatologice, a comparat ibuprofenul şi paracetamolul în durerea dentară la copii. Acest studiu a arătat că o doză de ibuprofen de 400 mg administrată înaintea intervenţiei şi una identică la 6 ore după aceasta a asigurat o reducere a durerii mai mare decât schema similară cu $1.000 \mathrm{mg}$ de paracetamol (6).

Pentru faza acută a durerii de cap în copilărie, paracetamolul şi ibuprofenul sunt cele mai folosite $(13,31)$. Mai multe studii clinice au demonstrat efi- 
cacitatea ibuprofenului în reducerea cefaleei în 2 ore postadministrare $(3,8)$. Doar câteva studii au comparat ibuprofenul $(10 \mathrm{mg} / \mathrm{kg}) \mathrm{cu}$ alte medicamente. Dintre acestea, studiul condus de Hämäläinen şi colab. (1997) (10) a comparat eficacitatea ibuprofenului cu placebo şi cu paracetamolul (15 $\mathrm{mg} / \mathrm{kg}$ ), concluzionând că eficacitatea ibuprofenului a fost mai mare comparativ cu paracetamolul.

Pentru durerea musculo-scheletică posttraumatică, ibuprofenul s-a dovedit de asemenea foarte util (15). Cea mai recentă evaluare sistematică (16) a literaturii a selectat 8 studii clinice controlate, randomizate (SDORC), în care au fost înrolaţi 1.169 de copii (cu vârsta cuprinsă între 3 şi 8 ani). Această evaluare a arătat că ibuprofenul este un analgezic mai intens comparativ cu paracetamolul sau codeina, fiind echivalent $\mathrm{cu}$ asocierea dintre cele două substanţe active şi cu mai puţine efecte adverse. Un studiu publicat de Clark şi colab. (2007) (6) privind tratarea durerii acute din trauma musculoscheletică la copii şi adolescenţi (cu vârsta cuprinsă între 6 şi 17 ani), în care s-au administrat doze unice de paracetamol $(15 \mathrm{mg} / \mathrm{kg})$, ibuprofen $(10 \mathrm{mg} /$ $\mathrm{kg})$ şi codeină $(1 \mathrm{mg} / \mathrm{kg})$, a arătat o mai mare îmbunătăţire a scorului durerii după administrarea ibuprofenului faţă de celelalte două medicamente. Alt studiu clinic (7), efectuat pe 336 de copii cu afectare musculo-scheletică şi fracturi ale membrelor, a subliniat o reducere echivalentă a durerii pentru ibuprofen şi pentru asocierea paracetamol-codeină, dar cu mai multe reacţii adverse în cazul asocierii celor două substanţe active. În 2014, Poonai şi colab. (29) au comparat acţiunea analgezică a morfinei şi ibuprofenului la 134 copii cu fracturi necomplicate de membre, concluzionându-se că eficacitatea analgezică a fost comparabilă.

Pentru durerea postchirurgicală se porneşte de la constatarea că $40-60 \%$ dintre cazurile de sindroame dureroase după intervenţii la copii sunt subtratate din cauza dificultăţii estimării intensităţii durerii la nou-născut şi copilul mic, reticenţei în faţa potenţialelor reacţii adverse, precum şi numărului mic de analgezice aprobate pentru uz pediatric (4).

\section{Siguranța ibuprofenului în administrarea la copii}

Pentru ibuprofen, unul dintre cele mai studiate AINS la această categorie de subpopulaţie, a fost identificat cel mai mare profil de siguranţă şi eficacitate $(14,27)$. În lumina recentelor limitări privind folosirea opioidelor impuse de EMEA (2015) şi FDA (2017), reconsiderarea diferitelor analgezice include, în mod clar avantajos, ibuprofenul. În 2003, Kokki (30) a evaluat eficacitatea ibuprofenului în prevenirea durerii după intervenţii minore pentru hernii, fimoze, hidrocel şi hipospadias prin randomizarea a 81 copii (cu vârsta cuprinsă între 1 şi 4 ani) care au primit ibuprofen rectal sau placebo în timpul anesteziei. Ibuprofenul a redus semnificativ durerea în primele ore după proceduri şi, de asemenea, a redus consumul de morfină (rezultate similare au fost obţinute şi de Stewart şi colab., 2012) (35). Dacă studii mai vechi (34) au comparat eficacitatea ibuprofenului cu asocierea paracetamol/codeină, avantajând asocierea în privinţa riscului redus de sângerare; cercetări retrospective recente $(2,8,17,21)$ au confirmat eficacitatea analgezică a ibuprofenului la copii în durerea postchirurgicală şi au infirmat creşterea riscului de sângerare.

Alte trei studii prospective la pacienţi pediatrici au evaluat siguranţa şi eficacitatea ibuprofenului în durerea postamigdalectomie la:

- Copii cu vârsta de 6-14 ani trataţi cu ibuprofen (24 mg/kg/zi), paracetamol (48 mg/kg/zi) sau asocierea alternantă a celor două medicamente timp de 48 ore după intervenţie (22). Studiul a demonstrat echivalenţa analgezică a celor trei regimuri de tratament.

- Copii amigdalectomizaţi cu vârsta cuprinsă între 6 şi 17 ani trataţi cu ibuprofen iv (10 $\mathrm{mg} / \mathrm{kg}$ ) sau placebo (24). Studiul clinic a constatat o reducere semnificativă a utilizării fentanilului fără risc de complicaţii, inclusiv de sângerare post chirurgicală.

- Copii în vârstă de 1-10 ani cu necesitate de amigdalectomie şi/sau adenoidectomie care au primit ibuprofen sau asocierea paracetamol/morfină (29). Rezultatele studiului au arătat o eficacitate analgezică similară, cu avantajul lipsei deprimării respiratorii induse de morfină, în cazul utilizării ibuprofenului.

Alte cercetări recente au poziţionat utilizarea ibuprofenului ca opţiune validă de reducere a utilizării opioidelor în tratarea durerii după asemenea intervenţii $(19,34)$.

Intr-un studiu prospectiv, placebo controlat, randomizat, dublu-orb, pentru a compara eficacitatea administrării profilactice a ibuprofenului, paracetamolului sau placebo pentru reducerea durerii postextracţie dentară la copii (45 de copii cu vârste cuprinse între 6 şi 12 ani), rezultatele au evidenţiat o eficacitate superioară pentru ibuprofen, la care s-au înregistrat scoruri mai mici ale durerii $(\mathrm{p}<0,05)$ comparativ cu paracetamolul. 


\section{CONCLUZII}

Ibuprofenul este un inhibitor neselectiv al COX1 şi COX2 si este utilizat la copii pe scară largă, în tratamentul febrei şi durerii de diferite etiologii. Li-

\section{BIBLIOGRAFIE}

1. Ashley PF, Parekh S, Moles DR, Anand P, MacDonald LC. Preoperative analgesics for additional pain relief in children and adolescents having dental treatment. Cochrane Database Syst Rev. 2016 Aug 8;(8):CD008392.

2. Bedwell JR, Pierce M, Levy M, Shah RK. Ibuprofen with acetaminophen for postoperative pain control following tonsillectomy does not increase emergency department utilization. Otolaryngol Head Neck Surg. 2014 Dec;151(6):963-6.

3. Bertin L, Pons G, d'Athis P, Lasfargues G, Maudelonde C, Duhamel JF, Olive G. Randomized, double-blind, multicenter, controlled trial of ibuprofen versus acetaminophen (paracetamol) and placebo for treatment of symptoms of tonsillitis and pharyngitis in children. J Pediatr. 1991 Nov;119(5):811-4.

4. Brasher C, Gafsous B, Dugue S, Thiollier A, Kinderf J, Nivoche Y, Grace R, Dahmani S. Postoperative pain management in children and infants: An update. Paediatr Drugs. 2014 Apr;16(2):129-40.

5. Chiappini E, Principi N, Mansi N, Serra A, De Masi S, Camaioni A, Esposito S, Felisati G, Galli L, Landi M, Speciale AM, Bonsignori F, Marchisio P, de Martino M; Italian Panel on the Management of Pharyngitis in Children. Management of acute pharyngitis in children: summary of the Italian National Institute of Health guidelines. Clin Ther. 2012 Jun;34(6):1442-1458.e2.

6. Clark E, Plint AC, Correll R, Gaboury I, Passi B. A randomized, controlled trial of acetaminophen, ibuprofen, and codeine for acute pain relief in children with musculoskeletal trauma. Pediatrics. 2007 Mar;119(3):460-7.

7. Drendel AL1, Gorelick MH, Weisman SJ, Lyon R, Brousseau DC, Kim MK. A randomized clinical trial of ibuprofen versus acetaminophen with codeine for acute pediatric arm fracture pain. Ann Emerg Med. 2009 Oct;54(4):553-60.

8. D'Souza JN, Schmidt RJ, Xie L, Adelman JP, Nardone HC. Postoperative nonsteroidal anti-inflammatory drugs and risk of bleeding in pediatric intracapsular tonsillectomy. Int J Pediatr Otorhinolaryngol. 2015 Sep;79(9):1472-6.

9. Goldman RD, Ko K, Linett LJ, Scolnik D. Antipyretic efficacy and safety of ibuprofen and acetaminophen in children. Ann Pharmacother. 2004 Jan;38(1):146-50.

10. Hämäläinen ML, Hoppu K, Valkeila E, Santavuori P. Ibuprofen or acetaminophen for the acute treatment of migraine in children: a double-blind, randomized, placebo-controlled, crossover study. Neurology. 1997 Jan;48(1):103-7.

11. Hay AD, Redmond NM, Costelloe C, Montgomery AA, Fletcher M, Hollinghurst S, Peters TJ. Paracetamol and ibuprofen for the treatment of fever in children: the PITCH randomised controlled trial. Health Technol Assess. 2009 May;13(27):iii-iv, ix-x, 1-163.

12. Jackson LA, Dunstan M, Starkovich P, Dunn J, Yu O, Nelson JC, Rees T, Zavitkovsky A. Prophylaxis with acetaminophen or ibuprofen for prevention of local reactions to the fifth diphtheria-tetanus toxoids-acellular pertussis vaccination: a randomized, controlled trial. Pediatrics. 2006 Mar;117(3):620-5.

13. Jeric M, Surjan N, Jelicic Kadic A, Riva N4, Puljak L. Treatment of acute migraine attacks in children with analgesics on the World Health Organization Essential Medicines List: A systematic review and GRADE evidence synthesis. Cephalalgia. 2018 Aug;38(9):1592-1607.

14. Kanabar DJ. A clinical and safety review of paracetamol and ibuprofen in children. Inflammopharmacology. 2017;25:1-9.

15. Korownyk C, Young J, Michael Allan G. Optimal pain relief for pediatric MSK injury. Can Fam Physician. 2015 Jun;61(6):e276.

16. Le May S, Ali S, Khadra C, Drendel AL, Trottier ED, Gouin S, Poonai N. Pain Management of Pediatric Musculoskeletal Injury in the teratura de specialitate conţine date vaste care susţin siguranţa şi eficacitatea ibuprofenului administrat ca medicament OTC.

Conflict of interest: none declared Financial support: none declared

Emergency Department: A Systematic Review. Pain Res Manag. 2016;2016:4809394.

17. Liu $C$ and Ulualp SO. Outcomes of an alternating ibuprofen and acetaminophen regimen for pain relief after tonsillectomy in children. Ann Otol Rhinol Laryngol. 2015;124:777-781.

18. Magni AM, Scheffer DK, Bruniera P. Antipyretic effect of ibuprofen and dipyrone in febrile children. J Pediatr (Rio J). 2011 JanFeb;87(1):36-42.

19. Mahgoobifard M, Mirmesdagh Y, Imani F, Najafi A, Nataj-Majd M. The analgesic efficacy of preoperative oral ibuprofen and acetaminophen in children undergoing adenotonsillectomy: A randomized clinical trial. Anesth Pain Med. 2014 Feb 28;4(1):e15049. doi: 10.5812/ aapm. 15049 .

20. Manley J, Taddio A. Acetaminophen and ibuprofen for prevention of adverse reactions associated with childhood immunization. Ann Pharmacother. 2007 Jul;41(7):1227-32.

21. Mattos JL, Robison JG, Greenberg J, Yellon RF. Acetaminophen plus ibuprofen versus opioids for treatment of post-tonsillectomy pain in children. Int J Pediatr Otorhinolaryngol. 2014 Oct;78(10):1671-6.

22. Merry AF, Edwards KE, Ahmad Z, Barber C, Mahadevan M, Frampton C. Randomized comparison between the combination of acetaminophen and ibuprofen and each constituent alone for analgesia following tonsillectomy in children. Can J Anaesth. 2013 Dec;60(12):1180-9.

23. Moore PA, Acs G, Hargreaves JA. Postextraction pain relief in children: A clinical trial of liquid analgesics. Int $J$ Clin Pharmacol Ther Toxicol. 1985 Nov;23(11):573-7.

24. Moss JR, Watcha MF, Bendel LP, McCarthy DL, Witham SL, Glover CD. A multicenter, randomized, double-blind placebo-controlled, single dose trial of the safety and efficacy of intravenous ibuprofen for treatment of pain in pediatric patients undergoing tonsillectomy. Paediatr Anaesth. 2014 May;24(5):483-9.

25. Paul IM, Sturgis SA, Yang C, Engle L, Watts H, Berlin CM Jr. Efficacy of standard doses of Ibuprofen alone, alternating, and combined with acetaminophen for the treatment of febrile children. Clin Ther. 2010 Dec;32(14):2433-40.

26. Perrott DA, Piira T, Goodenough B, Champion GD. Efficacy and safety of acetaminophen vs ibuprofen for treating children's pain or fever: a meta-analysis. Arch Pediatr Adolesc Med. 2004 Jun;158(6):521-6.

27. Pierce CA, Voss B. Efficacy and safety of ibuprofen and acetaminophen in children and adults: a meta-analysis and qualitative review. Ann Pharmacother. 2010;44:489-506.

28. Poddighe D, Brambilla I, Licari A, Marseglia GL. Ibuprofen for Pain Control in Children: New Value for an Old Molecule. Pediatr Emerg Care. 2018 Jun 14. doi: 10.1097/PEC.0000000000001505.

29. Poonai N, Datoo N, Ali S, Cashin M, Drendel AL, Zhu R, Lepore N, Greff M, Rieder M, Bartley D. Oral morphine versus ibuprofen administered at home for postoperative orthopedic pain in children: A randomized controlled trial.CMAJ. 2017 Oct 10;189(40):E1252-E1258.

30. Richer L, Billinghurst L, Linsdell MA, Russell K, Vandermeer B, Crumley ET, Durec T, Klassen TP, Hartling L. Drugs for the acute treatment of migraine in children and adolescents. Cochrane Database Syst Rev. 2016 Apr 19;4:CD005220.

31. Sarrell EM, Wielunsky E, Cohen HA. Antipyretic treatment in young children with fever: acetaminophen, ibuprofen, or both alternating in a randomized, double-blind study. Arch Pediatr Adolesc Med. 2006 Feb;160(2):197-202.

32. Schlachtel BP, Thoden WR. A placebo-controlled model for assaying systemic analgesics in children. Clin Pharmacol Ther. 1993;53:593-601. 
33. Sjoukes A, Venekamp RP, van de Pol AC, Hay AD, Little P, Schilder AG, Damoiseaux RA. Paracetamol (acetaminophen) or non-steroidal anti-inflammatory drugs, alone or combined, for pain relief in acute otitis media in children. Cochrane Database Syst Rev. 2016 Dec 15;12:CD011534.

34. St Charles CS, Matt BH, Hamilton MM, Katz BP. A comparison of ibuprofen versus acetaminophen with codeine in the young tonsillectomy patient. Otolaryngol Head Neck Surg. 1997 Jul;117(1):76-82
35. Stewart DW, Ragg PG, Sheppard S, Chalkiadis GA. The severity and duration of postoperative pain and analgesia requirements in children after tonsillectomy, orchidopexy, or inguinal hernia repair. Paediatr Anaesth. 2012 Feb;22(2):136-43.

36. Wong T, Stang AS, Ganshorn H, Hartling L, Maconochie IK, Thomsen AM, Johnson DW. Combined and alternating paracetamol and ibuprofen therapy for febrile children. Evid Based Child Health. 2014 Sep;9(3):675-729. 